\title{
Sexualidade e gênero(s): debates e desafios no estágio de licenciatura em psicologia
}

\author{
Sheila Daniela Medeiros dos Santos', https://orcid.org/0000-0002-0565-7330 \\ Jordana de Castro Balduino Paranahyba1', https://orcid.org/0000-0002-8718-8944
}

\begin{abstract}
Resumo
Este artigo objetiva apresentar e problematizar uma experiência de estágio de licenciatura em Psicologia consolidada através de um projeto de extensão (minicurso) destinado aos jovens de uma instituição de educação profissional técnica de nível médio, localizada na região central do município de Goiânia. Esta experiência, implementada pelos licenciandos(as) do curso de Psicologia da Universidade Federal de Goiás, efetivouse a partir do referencial teórico de Pandita-Pereira (2013) e Sekkel (2010). As análises dos dados mostraram que a elaboração de projetos de extensão no estágio de licenciatura em Psicologia consolida-se como uma proposta inovadora, uma vez que os(as) licenciandos(as), as professoras formadoras (docentes universitárias) e a comunidade escolar têm a possibilidade de se apropriarem coletivamente de conhecimentos que transformam as suas concepções teóricas conscientizando-se do papel que possuem como sujeitos históricos na luta contra as formas opressoras que discriminam e estigmatizam os indivíduos considerados diferentes em uma sociedade normativa e excludente.
\end{abstract}

Palavras-chave: Psicologia; formação de professores; ensino médio.

\section{Sexuality and gender (s): discussions and challenges in the psychology study}

\begin{abstract}
This article aims to present and problematize a Bachelors degree internship experience in a consolidated psychology through an extension project (short course) aimed at young people of a medium-level technical vocational education institution located in the central region of the municipality of Goiânia. This experience, implemented by the graduates of the Psychology course at the Federal University of Goiás, was based on the theoretical reference of Pandita-Pereira (2013) and Sekkel (2010). The analysis of the data showed that the elaboration of extension projects in the degree course in Psychology is consolidated as an innovative proposal, since the students, the educating teachers (university professors) and the school community have the possibility of collectively appropriating knowledge that transforms their theoretical conceptions by becoming aware of their role as historical subjects in the struggle against oppressive forms that discriminate and stigmatize individuals considered different in a normative and exclusionary society.
\end{abstract}

Keywords: Psychology; teacher training; high school.

\section{Sexualidad y género(s): debates y retos en la pasantía de licenciatura en psicología}

\section{Resumen}

En este artículo se tiene por objetivo presentar y problematizar una experiencia de pasantía de licenciatura en Psicología consolidada por intermedio de un proyecto de extensión (taller) destinado a los jóvenes de una institución de educación profesional técnica de nivel secundaria, localizada en la región central del municipio de Goiania. Esta experiencia, implementada por los licenciandos (as) del curso de Psicología de la Universidad Federal de Goiás, se ha realizado a partir del referencial teórico de Pandita-Pereira (2013) y Sekkel (2010). Los análisis de los datos enseñaron que la elaboración de proyectos de extensión en la pasantía de licenciatura en Psicología se consolida como una propuesta innovadora, una vez que los licenciandos(as), las profesoras formadoras (docentes universitarias) y la comunidad escolar tienen la posibilidad de apropiarse colectivamente de conocimientos que transforman sus concepciones teóricas concientizándose del papel que poseen como sujetos históricos en la lucha en contra las formas opresoras que discriminan y estigmatizan los individuos considerados diferentes en una sociedad normativa y excluyente.

Palabras clave: Psicología; formación del profesor; enseñanza secundaria.

1 Universidade Federal de Goiás, Faculdade de Educação - Goiânia - Goiás, Brasil. 


\section{Introdução}

Este artigo foi produzido no âmbito de uma proposta de intervenção desenvolvida nas disciplinas: Estágio Supervisionado em Formação do Professor de Psicologia I e II, oferecidas pelo curso de Licenciatura em Psicologia da Universidade Federal de Goiás (UFG), em Goiânia.

A referida proposta consolidou-se através de um projeto de extensão (minicurso) destinado aos jovens de uma instituição de educação profissional técnica de nível médio, localizada na região central do município de Goiânia-GO.

Para viabilizar essa proposta procurou-se considerar as questões complexas que emergiam na sociedade brasileira atual, as normatizações referentes ao curso de licenciatura em Psicologia e o histórico da Psicologia no Ensino Médio no Brasil.

A partir dessas considerações, no intuito de compreender os fundamentos teóricos e metodológicos em que esta proposta foi edificada, procurou-se no presente artigo, primeiramente, problematizar alguns aspectos relacionados à regulamentação da licenciatura em Psicologia no Brasil, a fim de que posteriormente fosse possível apresentar o contexto e a proposta de intervenção elaborada pelos licenciandos(as) em Psicologia da Universidade Federal de Goiás. Por último, o artigo enfatiza a relevância de criar espaços e processos de ensino, pesquisa e extensão no campo de estágio para que os estudantes do curso de licenciatura em Psicologia possam desenvolver condições propícias à produção do conhecimento e à continuidade da própria atividade formativa, consubstanciadas pela compreensão da função social do contexto de atuação no sentido da formação humana e da concretização da cidadania.

\section{Licenciatura em Psicologia: da tramitação à consolidação de propostas legais}

Para que seja exequível a compreensão da licenciatura como uma habilitação fundamental aos cursos de Psicologia no Brasil, faz-se necessário realizar uma breve contextualização em relação às mudanças ocorridas nos documentos oficiais no que diz respeito às diretrizes curriculares.

A partir do momento em que a profissão e o curso de graduação em Psicologia foram oficialmente regulamentados, em 1962, e após o Conselho Federal de Educação expedir o Parecer $n^{\circ} 403$, aprovado em 12 de dezembro de 1962, que definia o currículo mínimo de Psicologia consolidando os direitos do exercício profissional, os cursos de Psicologia começaram a ofertar a formação acadêmica em três níveis, cada qual com duração e foco distintos: o bacharelado (04 anos), priorizando a formação do pesquisador; a licenciatura (04 anos), estabelecendo a formação do professor de Psicologia; e a formação do psicólogo (05 anos), remetendo à formação profissional.

Entretanto, com a Resolução n 08, de 07 de maio de 2004, os cursos de graduação em Psicologia passaram a oferecer somente uma possibilidade de formação do psicólogo no Brasil, de tal forma que a oferta da licenciatura se tornou opcional nas Instituições de Ensino Superior (IES).

Deste modo, após uma reforma curricular empreendida pela maioria dos cursos de graduação em Psicologia, a licenciatura deixou de ser oferecida, uma vez que o ensino de Psicologia foi excluído da grade curricular do Ensino Médio regular e, por conseguinte, o campo de atuação profissional dos licenciados deixou de representar um lugar preciso.

Contudo, em um clima de efervescência política instituído nos primeiros anos do século XXI, a inextricável e tensa relação histórica entre a Psicologia e a Educação passou a contar com uma nova legislação que intensificou os pontos nevrálgicos acerca do debate empreendido sobre a formação dos professores de Psicologia para a Educação Básica: a Resolução $n^{\circ}$ 5, de 15 de março de 2011, que instituiu as Diretrizes Curriculares Nacionais para os cursos de graduação em Psicologia.

De acordo com o artigo 13 , parágrafo $1^{\circ}$ dessa Resolução, o projeto pedagógico complementar para a Formação de Professores de Psicologia determinava alguns objetivos primordiais, dentro dos quais, se destacava aquele referente à complementação da formação dos psicólogos articulada aos saberes específicos da área com os conhecimentos didáticos e metodológicos para a atuação na construção de políticas públicas de educação (Resolução n 5, 2011).

Em face desta Resolução, o regresso da oferta obrigatória da formação de professores de Psicologia como complementar aos cursos de formação de psicólogos fez com que a Psicologia adquirisse novamente destaque no cenário das licenciaturas.

Essa obrigatoriedade, que ocorreu tanto no ensino privado como no ensino público, gerou questões instigantes a respeito dos possíveis campos de atuação do licenciado em Psicologia e de suas contribuições para a formação dos alunos da Educação Básica.

Em relação a este aspecto, Pandita-Pereira (2013) assevera que tanto os alunos como os coordenadores dos cursos de Psicologia questionavam de modo incisivo: Por que, para quem e para quê ensinar Psicologia no ensino médio?

Cabe salientar que essas questões, inegavelmente, fomentam debates que levam os profissionais de licenciatura em Psicologia a redimensionarem as concepções que possuem de: sociedade, educação, docência, currículo, juventude, formação humana, entre outras, as quais se não estiverem devidamente problematizadas podem conduzir à visões levianas e generalistas sobre a formação de professores e sobre a real situação das escolas no Brasil.

Nesse contexto, Coelho (2003) critica uma formação de professores que visa apenas atender a uma demanda de mercado, em que posturas inspiradas no tecnicismo são priorizadas. De acordo com esse autor, deve-se problematizar a formação do professor de Psicologia para não cair no engodo de relacionar a educação à ideia de uma intervenção técnica, que prepara os alunos para um mercado de trabalho em que o sentido da educação e do fazer pedagógico são desqualificados. 
Convém ressaltar que a formação do professor de Psicologia adquiriu maior relevância com a proposta do Projeto de Lei n 105/2007 (2007) que defendia a inserção da Psicologia como disciplina curricular no Ensino Médio. Esse projeto de lei, ao ser apoiado por instâncias organizacionais, como: a Associação Brasileira do Ensino de Psicologia (ABEP); a Associação Brasileira de Psicologia Escolar e Educacional (ABRAPEE); o Conselho Federal de Psicologia (CFP) e o Fórum de Entidades Nacionais de Psicólogos Brasileiros (FENPB), deu origem à campanha denominada: Oito Razões para aprender Psicologia no Ensino Médio (ConseIho Regional de Psicologia de São Paulo, 2008), lançada em meados de 2008.

É indubitável considerar que o Ensino Médio, como um campo de atuação do professor de Psicologia, passou a ocupar um lugar privilegiado nas discussões acerca das contribuições do ensino de Psicologia na Educação Básica.

Por outro lado, a Psicologia no Ensino Médio mesmo estando presente em outros momentos históricos do país, seja no ensino regular ou no ensino profissionalizante, como demonstraram Soligo e Azzi (2009), não conseguiu firmar-se como um campo sólido, uma vez que "a licenciatura e as discussões sobre o ensino de Psicologia no nível médio e geral historicamente ocuparam um lugar marginal na graduação" (Pandita-Pereira \& Sekkel, 2012, p. 974).

Os conteúdos da Psicologia, embora estivessem cada vez mais presentes no currículo do ensino básico, apresentavam-se como temas transversais em diferentes disciplinas ou projetos coordenados por professores de distintas áreas do conhecimento.

Ademais, se por um lado o estado de São Paulo pôde ilustrar os diversos momentos históricos do ensino de Psicologia no Ensino Médio, seja como disciplina obrigatória, optativa, ou integrante do núcleo diversificado do currículo (Dadico, 2009; Pandita-Pereira \& Sekkel, 2012), por outro lado, o estado de Goiás não apresentou em sua trajetória experiência semelhante, uma vez que a disciplina de Psicologia nunca integrou o currículo obrigatório do Ensino Médio.

Apesar desse histórico diferenciado, quando comparado ao do estado de São Paulo, nota-se que o curso de Psicologia da FE/UFG, campus Goiânia-GO, desde a sua criação, apresentou em sua matriz curricular um projeto pedagógico complementar em Formação do Professor de Psicologia com núcleo comum a todas as licenciaturas da instituição.

Desse modo, o projeto de licenciatura oferecido pelo curso de Psicologia da FE/UFG, e sua culminação nas atividades de estágio, possibilitou a aproximação dos(as) licenciandos(as) de Psicologia com o Ensino Médio, não apenas no sentido de repensarem criticamente as contribuições que os conteúdos dessa área do conhecimento poderiam oferecer à Educação Básica, mas também no intuito de construírem uma nova visão de homem, constituído historicamente nas/pelas relações sociais em contextos culturais específicos.

\section{Nas trilhas da licenciatura em Psicologia: o contexto de uma experiência}

Ao considerar que a atividade primordial do estágio de licenciatura em Psicologia da FE/UFG é a de consolidar o planejamento e a execução de um projeto de extensão com ênfase na práxis docente, no ano de 2013, sistematizou-se uma proposta de minicurso a ser oferecido em uma instituição de educação profissional técnica de nível médio localizada na região central do município de Goiânia-GO.

A presente proposta de intervenção foi desenvolvida durante as disciplinas de Estágio Supervisionado em Formação do Professor de Psicologia I e Estágio Supervisionado em Formação do Professor de Psicologia II, do curso de Licenciatura em Psicologia da Faculdade de Educação da Universidade Federal de Goiás.

Nessas disciplinas os(as) licenciandos(as) tiveram a possibilidade de estudar questões pertinentes à docência e à formação inicial e continuada de professores de Psicologia a partir de aulas expositivas dialogadas, atividades individuais e em grupo, discussão de filmes e documentários, debates e da realização de um júri simulado sobre a reinserção, ou não, da Psicologia no Ensino Médio.

A proposta inicial foi a de que os(as) licenciandos(as) analisassem criticamente, em uma perspectiva histórica, a relação entre Psicologia e Educação, a dialeticidade entre teoria e prática e os limites, as possibilidades e as implicações dessas relações para a práxis docente. Na sequência, empreenderam um intenso debate acerca da licenciatura no âmbito das reformulações curriculares dos cursos de Psicologia (Amado, 2013) e problematizaram os desafios e as perspectivas atuais para a formação do professor de Psicologia no ensino médio e em outros campos de atuação, com foco nos processos educativos, nos saberes e na prática social mediadora (Sekkel, 2010).

Nesse contexto, os estudantes examinaram algumas concepções de estágio e de docência (Pimenta \& Lima, 2006) com o intuito de delimitarem o referencial teórico que sustentaria a práxis pedagógica na instituição de ensino, campo de estágio.

Concomitante, ao considerarem que toda práxis pedagógica possui implícita uma dimensão ético-política e, ainda, que os distintos campos de estágio constituem o locus da experiência investigativa e da produção do conhecimento, os(as) licenciandos(as) optaram por uma das instituições de ensino (campos de estágio) que possuíam convênio com a Universidade Federal de Goiás. A partir dessa escolha se organizaram em grupos, a fim de estudarem os textos específicos para a população atendida.

Convém mencionar que, para discorrer detalhadamente sobre essa experiência educativa, optou-se por descrever o projeto de extensão (minicurso) elaborado por um grupo de alunos(as) (Barbosa \& cols., 2013) que realizou o estágio em uma instituição de ensino público que oferecia educação profissional técnica de nível médio. 
Em razão disso, o referido grupo de alunos(as) analisou as bases legais que regiam as Diretrizes Curriculares Nacionais para o Ensino Médio, Resolução n 02 de 30 de Janeiro de 2012 e as Diretrizes Curriculares Nacionais para a Educação Técnica Profissional de Nível Médio, Resolução $n^{\circ} 06$, de 20 de Setembro de 2012 ..

Conforme preconizam as pesquisas em educação (Lüdke \& André, 1986), os(as) licenciandos(as) observaram, descreveram e analisaram o campo de estágio, utilizando diferentes procedimentos de pesquisa, como: registros de observação, entrevistas com roteiro estruturado e semiestruturado, análise documental e iconográfica, entre outras técnicas de pesquisa.

Para efetivar este estudo, realizaram também o levantamento de dados que subsidiaram a compreensão da organização do espaço físico, do funcionamento administrativo-pedagógico, dos aspectos históricos, políticos, sociais e econômicos e das relações que se estabeleciam entre a instituição de educação escolar e a comunidade. Posteriormente, empreenderam as análises do material empírico, ao mesmo tempo em que demarcaram o campo teórico onde o trabalho iria transitar.

A partir da diagnose da realidade observada e com o intuito de trabalhar um dos problemas emergentes no contexto das contradições atuais, os(as) licenciandos(as) optaram por desenvolver um projeto de extensão que apresentou como aspecto nuclear a temática: Sexualidade e gênero(s) no mundo contemporâneo, em razão de ter surgido como algo recorrente durante as observações e os diálogos com os(as) alunos(as), os professores, as psicólogas (supervisoras do campo de estágio) e os demais profissionais da escola.

Para esclarecer o lugar teórico em que os conceitos de sexualidade e gênero se situariam no trabalho, os(as) licenciandos(as) elegeram como prioridade inicial adentrar nas definições desses termos, os quais, por sua vez, se apresentavam como polissêmicos e complexos, dado o seu caráter histórico. Para isso, eles buscaram referências em periódicos junto à Biblioteca Virtual em Saúde (BVS), uma das mais acessadas na área da Psicologia, e em livros que constavam na base de dados da Biblioteca Nacional, depositária do patrimônio bibliográfico e documental do Brasil.

A partir do entrecruzamento de palavras-chave e da seleção de filtros para refinar a busca da pesquisa, os(as) licenciandos(as) selecionaram títulos que pudessem auxiliá-los a compreender o modo como os termos sexualidade e gênero estavam sendo referenciados nos estudos que envolviam a temática.

Nesse momento, foi possível perceber que dentre a diversidade de definições possíveis, as filiações teórico-epistemológicas apontavam para debates controversos que incluíam, fundamentalmente, perspectivas pós-estruturalistas, diálogos com a psicanálise e discussões sobre as adequações metodológicas que os conceitos exigiam.

As obras de autores como Altmann e Martins (2007), Butler (2003), Foucault (1997), Louro (2011), Nicholson (2000) e Scott (1995), possibilitaram aos(às) licenciandos(as) avanços teóricos no momento de delinearem o escopo do projeto de extensão.
No que tange ao trabalho desenvolvido, os(as) licenciandos(as) depreenderam, conforme as preleções de Nicholson (2000) e Butler (2003) que o gênero não pode ser concebido meramente como uma inscrição cultural sobre um sexo previamente dado, uma vez que ele é multíplice e está relacionado a outros elementos de diferenciação como classe, raça/etnia, geração, desejo, subjetividade e experiência histórica.

Para Scott (1995), o gênero pressupõe o modo como os grupos culturais, em dada sociedade, dramatizam o binarismo sexual rechaçando as imposições biológicas da natureza. Nessa direção, a diversidade supera os binarismos e as matrizes identitárias impostas socialmente, instituindo coalizações por afinidades. Segundo Butler (2003), o gênero se refere à significação cultural pela qual a 'natureza sexuada' é produzida.

Cabe salientar que estas proposições permitem pensar a sexualidade como construção social e histórica que implica certa conexão com as relações de poder, uma vez que, para Foucault (1997, pp. 145-146), "é pelo sexo efetivamente, ponto imaginário fixado pelo dispositivo de sexualidade, que todos devem passar para ter acesso à sua própria inteligibilidade ..., à totalidade de seu corpo..., à sua identidade".

Nessa perspectiva, faz-se necessário romper as normas codificadas, os paradigmas morais e os modelos corpóreos conservadores que concebem a sexualidade como o eixo central da identidade e do ser no mundo, no qual fundamentam-se valores institucionais como procriação, casamento e família cunhados em um contexto de heteronormatividade.

Para sustentar essa linha de argumentação, Butler (2003) pontua análises instigantes ao asseverar que o gênero cria o sexo e não o contrário. Portanto, essa perspectiva permite, de modo desafiador, desconstruir a ilusória evidência do sexo biológico como demarcador de limites identitários.

Cumpre lembrar, ainda de acordo com Altmann e Martins (2007), que o tema sexualidade durante muito tempo foi ignorado pela escola, de tal maneira que a sua discussão sempre se limitou ao fórum restrito dos jovens. No entanto, a epidemia de AIDS e a disseminação da gravidez precoce, deram a visibilidade necessária à sexualidade juvenil, fomentando a criação de diversos projetos de educação sexual nas escolas e a proposição de um tema transversal sobre educação sexual nos Parâmetros Curriculares Nacionais - PCNs (Altmann \& Martins, 2007).

Por outro lado, Altmann e Martins (2007) esclarecem que não basta trazer o tema da educação sexual para as escolas, já que a maioria delas restringe a apresentação da sexualidade e do(s) gênero(s) às disciplinas de ciências e biologia, fundamentando-a em uma visão biológica que prioriza somente a descrição dos órgãos sexuais e de suas funções reprodutivas.

Em contraposição, a sexualidade e o(s) gênero(s) não podem se limitar a explicações deterministas biológicas, já que a constituição de homens e mulheres e a maneira como cada sujeito vive sua sexualidade são construídas no interior de cada cultura e em contextos históricos específicos, não 
sendo possível pensar em uma definição de homem como algo essencialmente natural (Louro, 2011).

Ao considerar os conteúdos com ênfase na sexualidade e no(s) gênero(s) nota-se, atualmente, que pela dificuldade de se trabalhar o tema na escola (re)produz-se, na maioria das vezes, um ensino que contribui para legitimar/ disseminar uma visão biologicista, preconceituosa e dicotômica da temática em pauta.

Desse modo, uma das contribuições do ensino de Psicologia, na escola, pode ser a de forjar uma visão que rompa com a cisão entre o normal e o patológico, o certo e o errado, o bom e o ruim, e que institua uma ampla discussão a respeito das diferenças e dos desejos do homem, como um ser que ocupa um corpo biológico que não se desenvolve de forma linear e previsível, mas que indubitavelmente é um ser cultural, que adquire a condição humana através das relações sociais.

\section{Processos formativos e temáticas desafiadoras}

Para viabilizar o projeto de extensão, os(as) licenciandos(as) elaboraram a proposta de um minicurso intitulado: A namorada da mãe de João: sexualidade e gênero na atualidade, uma vez que na sociedade contemporânea multiplicam-se os modos de compreender, atribuir significação e experienciar a sexualidade e o(s) gênero(s) e não se pode continuar a ter como referência simplesmente os esquemas binários, baseados no masculino/feminino, e normativos, fundamentados na orientação sexual definida como heterossexual.

Em relação a esse aspecto, de acordo com Louro (2004), no campo do(s) gênero(s) e da sexualidade, o grande desafio é aceitar as distintas posições de ambiguidade entre as identidades, é admitir que as fronteiras sexuais e de gênero(s) são constantemente atravessadas e que o lugar social no qual alguns indivíduos vivem é justamente a fronteira. Em outros termos, o desafio é reconhecer que não existe o anormal, existe o diferente e que já não se pode ignorar a longa história de marginalização e de repressão que os indivíduos que vivem na 'fronteira' enfrentaram e ainda enfrentam atualmente.

Nesse contexto, o objetivo geral do minicurso foi o de apresentar, debater e compreender a construção da sexualidade e do(s) gênero(s), desnaturalizando os discursos biologicistas, admitindo a diferença e enfatizando o quão imprescindível é lutar pela construção de uma sociedade menos desigual e mais democrática.

As temáticas abordadas no minicurso, por sua vez, foram as seguintes: a construção da sexualidade e da identidade de gênero(s); as diversas formas de sexualidade e os discursos biologicistas; as representações sociais de gênero(s), a discriminação e o preconceito; a equidade de gênero(s) e as mudanças sociais.

Cumpre lembrar que o minicurso constituiu-se de 8 encontros de $2 \mathrm{~h}$, totalizando uma carga horária de $16 \mathrm{~h}$ e foi oferecido como atividade extracurricular aos estudantes do curso técnico integrado ao ensino médio no contraturno ao período das aulas regulares em que os alunos/cursistas estavam matriculados.

$\mathrm{Na}$ primeira aula, os(as) licenciandos(as) explicitaram aos alunos/cursistas que a proposta do minicurso não estaria vinculada a dogmas religiosos ou a doutrinas político-partidárias (Barbosa \& cols., 2013), uma vez que a intenção era a de realizar uma problematização coletiva desmistificando as diferenças e construindo valores e atitudes que permitissem um olhar crítico sobre as identidades de gênero(s) no sentido de lutarem contra a desigualdade, o preconceito e a discriminação.

Por tratar-se de uma atividade que realizar-se-ia no contraturno do período das aulas regulares e, ainda, pelo fato de grande parte dos alunos/cursistas serem menores de 18 anos, foi-lhes entregue um termo de consentimento que deveria ser assinado pelos pais ou responsáveis autorizando-os a realizarem o minicurso.

Nesse sentido, os diversos conceitos e possibilidades teóricas foram abordados de tal maneira que os alunos/ cursistas puderam assumir posicionamentos distintos a partir do embate de diferentes concepções e representações acerca da temática, tendo como sustentáculo a liberdade de expressão, o questionamento constante de suas vivências e o respeito aos direitos do outro, acima das divergências religiosas, raciais, étnicas, políticas, sexuais e/ou de gênero.

Sendo assim, os(as) licenciandos(as) promoveram o debate considerando aspectos como: a diferença entre sexo/ sexualidade e entre homossexualismo/homossexualidade; a identidade de gênero(s); a orientação sexual; a diversidade sexual, entre outros.

Para incitar o debate em uma das aulas, os(as) estagiários(as), sob a orientação da professora da disciplina (docente universitária), apresentaram dois casos sobre identidade de gênero(s) aos alunos/cursistas. Um deles referia-se ao caso de um aluno transexual em uma escola de ensino médio que havia sido proibido de usar o banheiro das meninas por exigência dos pais das estudantes, mas que também não podia usar o banheiro dos meninos, por sofrer retaliação e por vivenciar a condição de sentir-se/ver-se como menina e não menino (Cruz, 2011). O outro caso referia-se a um menino de três anos, em uma escola de educação infantil, que queria passar esmalte da cor vermelha nas unhas, mas a professora queria proibi-lo, por não saber como lidar com a situação (Faria, 2006).

Após o levantamento de diversos posicionamentos, como: 'João/Joana deveria usar o banheiro dos meninos, porque biologicamente era menino'; 'João/Joana deveria usar o banheiro das meninas, porque em termos psicológicos se sentia menina'; 'João/Joana deveria usar o banheiro da Diretora da escola'; e 'João/Joana deveria usar um banheiro unissex que seria construído propriamente para alunos/alunas que vivenciavam a mesma condição', os(as) licenciandos(as) foram orientados pela professora formadora (docente universitária) a elaborarem perguntas a partir das opiniões proferidas pelos alunos/cursistas, no intuito de analisarem criticamente se as possíveis soluções encontra- 
das não estariam pautadas em premissas classificatórias, segregadoras e patologizantes que implicavam na violação dos direitos do ser humano.

Já em relação ao outro caso apresentado, do menino de três anos que queria passar esmalte vermelho nas unhas em uma escola de Educação Infantil, os(as) licenciandos(as) iniciaram o debate com os alunos/cursistas a partir das questões: Podemos conceber as relações de gênero na infância? Por quais razões, situações semelhantes à vivenciada pela professora da educação infantil nos impactam de diferentes formas? Em que medida as diversas instâncias e os espaços sociais têm o poder de decidir e inscrever nos corpos das crianças e dos jovens marcas e normas a serem seguidas?

Nas nuances do debate instaurado, os alunos/cursistas identificaram o papel da infância e da juventude na construção da realidade social, analisaram o nexo entre a autonomia e a dependência nas atuais modificações sociais e, ainda, compreenderam que na sociedade brasileira contemporânea o valor da infância e da juventude permanece na rejeição da alteridade, da diversidade-diferença e na distância-estranheza entre o biológico e o cultural.

Nessa ambiência, os alunos/cursistas se envolveram de tal maneira nas discussões que os(as) licenciandos(as) sugeriram como proposta convidar um palestrante que pudesse debater o assunto de modo mais sistemático em um dos encontros. Como a sugestão foi consensualmente aceita pelos alunos/cursistas, optou-se por convidar um ativista dos direitos humanos e militante do movimento LGBTT (lésbicas, gays, bissexuais, travestis e transexuais) do estado de Goiás.

Convém salientar que o palestrante convidado estava vinculado a diversas organizações em defesa dos direitos humanos e a grupos de combate às Doenças Sexualmente Transmissíveis (DST's) na região Centro-Oeste, como: a Articulação Brasileira de Gays (ARTGAY), o Grupo 'Eles por Eles' - GO e a Comissão de Articulação com os Movimentos Sociais (CAMS).

O palestrante discorreu, com escopo teórico, sobre: sexualidade e identidade de gênero(s); elementos históricos que propiciam avanços políticos, sociais e legais, incluindo a consolidação do casamento gay e da adoção homoparental; fatos verídicos e dados estatísticos sobre crimes homofóbicos no Brasil; e, ainda, a relevância de enfatizar a luta pelo respeito à diversidade e à dignidade humana.

Durante o minicurso, os alunos/cursistas também assistiram ao filme europeu Ma vie en rose (Minha vida em rosa) (Berliner, 1997), ao vídeo indiano It's your fault (A culpa é sua) (Shetty, 2013) e a outros vídeos e documentários (Barbosa \& cols., 2013). No que diz respeito ao vídeo: $A$ culpa é sua, os(as) licenciandos(as) apresentaram questões relacionadas aos movimentos feministas (história, objetivos e mudanças nas configurações das relações sociais), além de problematizarem o lugar ocupado pela mulher na sociedade, o modo como é concebido o machismo no oriente/ocidente, a sexualidade heteronormativa, a educação sexista e a violência contra a mulher.

Os(as) licenciandos(as) apresentaram, também, diversos vídeos de propagandas, como: Avó das Havaianas,
Homem invisivel, Tulipan Condoms, entre outras (Barbosa \& cols., 2013) para abordarem o preconceito, a discriminação e as diferentes construções e concepções de gênero, no intuito de discutirem estratégias e formas de reivindicação para unificar a luta das mulheres e a transformação das relações sociais.

Outro momento crucial do minicurso ocorreu quando os alunos/cursistas apresentaram dúvidas e questionamentos acerca de conceitos, como: bissexualidade, cisgênero, queer, intersexualidade e pansexualidade (Nardi, Machado, \& Silveira, 2015).

Ao ter em conta que alguns desses conceitos, até então, eram inteiramente desconhecidos pelos(as) licenciandos(as), pela professora da disciplina (docente universitária) e pelas psicólogas supervisoras do campo de estágio, foi necessário que todos os envolvidos no processo ensino-aprendizagem empreendessem uma pesquisa minuciosa em relação a tais conceitos, a fim de que definições equivocadas não fossem apropriadas de tal forma que resultassem na legitimação de atitudes preconceituosas.

$\mathrm{Na}$ penúltima aula do minicurso, propôs-se aos alunos/cursistas uma atividade avaliativa que consistiu na criação de uma peça publicitária a ser apresentada na modalidade vídeo, já que a escola (campo de estágio) possuía laboratório de informática e seria interessante aproveitar os recursos tecnológicos disponíveis na atualidade. Para desenvolver essa atividade os alunos/cursistas deveriam expor aspectos nucleares trabalhados no minicurso que não estivessem consubstanciados por conteúdos preconceituosos, sexistas ou discriminatórios.

Sendo assim, no último encontro, os alunos/cursistas apresentaram vídeos demasiadamente criativos em que eles próprios foram os protagonistas das cenas: um perfume denominado 'Incógnita' tanto para os meninos, como para as meninas; um detergente chamado 'Coroa' tanto para a Rainha como para o Rei do lar; e uma televisão Led HDTV para 'unir a família' de diversas configurações (homo)parentais (Barbosa \& cols., 2013), distintas daquelas baseadas tão somente no modelo de família nuclear burguesa imposto historicamente e legitimado de modo veemente pelo ideário neoliberal e pós-moderno.

\section{Considerações Finais}

Ao considerar a experiência de estágio de licenciatura em Psicologia realizada na instituição de educação profissional técnica de nível médio, nota-se que o projeto de extensão implementado possibilitou uma contribuição ímpar ao processo formativo dos(as) licenciandos(as), pelo fato de ter propiciado a práxis educativa na realidade da escola pública brasileira onde a relação entre teoria e prática é refletida continuamente e impossibilitada de dicotomização.

Além disso, o compromisso ético, político e epistemológico ao trabalhar a temática sexualidade e gênero(s) no projeto de extensão a partir de um conhecimento científico sistematizado, contribuiu para o processo de desnaturaliza- 
ção e desconstrução de uma visão biologicista da temática, em defesa de uma visão histórica e cultural como essencial.

De fato, problematizar essa concepção na escola faz parte do trabalho do professor de Psicologia de ir além das aparências, do sendo comum, do conhecimento tácito e do modelo natural/biológico, possibilitando o entendimento dos múltiplos determinantes dos fenômenos da subjetividade e da individualidade humana.

Dessa forma, o projeto de extensão (minicurso) realizado em uma instituição da Educação Básica, juntamente com os estudos teóricos e as reflexões da prática educativa viabilizadas na universidade, promoveu uma análise crítica a respeito das concepções presentes na formação do professor e uma compreensão da educação no seu sentido mais amplo, como prática social.

A contribuição deste projeto de extensão, portanto, transcende um determinado campo de atuação ou um determinado tema, pois traz discussões a respeito da prática social constitutiva da relação indivíduo e sociedade.

A partir do projeto de extensão, foi possível notar, ainda, que apesar das exigências e das demandas administrativas, estruturais, políticas, sociais e relacionais presentes no contexto escolar, não se pode permitir que as diferenças ligadas às relações de gênero(s) e à outras formas de exclusão continuem sendo ignoradas e produzindo silenciamentos no cotidiano da escola.

Em sentido oposto, é necessário que se compreenda: o contexto histórico e cultural em que a sexualidade e o(s) gênero(s) se tornaram uma questão para todos nós; as possibilidades de lidar com a diversidade no cotidiano da escola; a constituição dos indivíduos consubstanciada nas normas sociais; e os aspectos ideológicos a serem desvendados e enfrentados diante do fato de um aluno não ter lugar na escola, nem mesmo para utilizar um banheiro. Esses aspectos constituem pontos nodais que devem ser enfrentados no coletivo por toda a comunidade escolar (diretor, professores, especialistas, demais funcionários da escola, alunos, pais).

Acrescenta-se a estes desafios destacados no tempo em que se deu a realização do projeto de extensão (minicurso), um outro que se faz presente na atualidade e que constitui mais uma peça de desmonte social: a aprovação da Lei $n^{\circ} 13.415$ de 16 de fevereiro de 2017, referente à conversão da Medida Provisória $n^{\circ} 746 / 16$ da reforma do Ensino Médio (Lei n 13.415, 2017). Trata-se de uma lei que expressa uma hegemonia neoliberal, pensada para uma sociedade elitista e fragmentária, em que o aluno obrigatoriamente faz o Ensino Médio integral, podendo optar por áreas nas quais (supostamente) tenha 'vocação', desconsiderando as condições dos diferentes municípios e suas escolas e o perfil do jovem trabalhador brasileiro. A nova legislação também prevê, dentre outros afrontamentos, uma formação técnica de nível médio que incide dentro da carga horária do ensino regular integral e com disciplinas que podem ser ministradas por profissionais 'de notório saber' em sua área de atuação.

Cumpre lembrar que, em meio às diversas críticas que vem sendo apontadas a esta Lei por diferentes segmentos da sociedade, se destaca, para o presente trabalho, as implica- ções direcionadas para uma formação tecnicista e pragmática em oposição a uma formação crítica dos estudantes.

De acordo com a ex-presidente da Associação Nacional de Pós-Graduação e Pesquisa em Educação (ANPED, 2016), professora Maria Margarida Machado da Universidade Federal de Goiás, a proposta que deu origem a Lei não pode ser considerada como um investimento em educação técnica, mas ao contrário representa uma deturpação da educação profissional; afinal, sabe-se que as escolas técnicas exigem investimentos (como laboratórios, bibliotecas e equipamentos), professores concursados com formação na área de atuação e um currículo que integre Ciência, Cultura e Tecnologia. Com isso, as conquistas árduas, e ainda carentes de recursos financeiros, dos Institutos Federais, mais uma vez se encontram ameaçadas por uma Lei que precariza e torna ainda mais aligeirado o ensino em nosso país.

Em outros termos, a reformulação do Ensino Médio 'deforma' a educação, reforçando as diferenças sociais, desvalorizando a classe trabalhadora e reafirmando a continuidade de uma sociedade classista, fragmentada e preconceituosa.

Portanto, nos trilhos das transformações em curso, considera-se a proposta de elaborar um projeto de extensão na disciplina Estágio Supervisionado em Formação de Professores de Psicologia como algo inovador, uma vez que a cada ano, os(as) licenciandos(as), as professoras formadoras (docentes universitárias) e toda a comunidade escolar (diretor, professores, especialistas, demais funcionários da escola, alunos, pais), têm a possibilidade de, coletivamente, se apropriarem de conhecimentos que transformam as suas concepções e propiciam a conscientização do papel fundamental que possuem como sujeitos históricos na luta contra as formas opressoras que se instauram a partir das relações sociais entre os indivíduos em uma sociedade que imperativamente ainda se desvela como normativa, desigual e excludente.

\section{Referências}

Altmann, H.; Martins, C.J. (2007). Políticas da sexualidade no cotidiano escolar. In: Camargo, A.M.F.; Mariguela, M. (Orgs.), Cotidiano escolar emergência e invenção (pp. 131-150). Piracicaba: Jacintha Editores.

Amado, A.C.S. (2013). O ensino de Psicologia: o cenário atual. In: Sekkel, M.C.; Barros, C.C. (Orgs.), Licenciatura em Psicologia: temas atuais (pp. 77-94). Editora Zagodoni.

Associação Nacional de Pós-Graduação e Pesquisa em Educação [ANPED] (2016). Entrevista com a Professora Margarida Machado (UFG), ex-presidente da ANPED, sobre a Reformulação do Ensino Médio, 19/09/2016. Recuperado: 14 ago. 2017. Disponível: http:// www.anped.org.br/news/entrevista-com-professora-margaridamachado-ufg-ex-presidente-da-anped-sobre-reformulacao-do.

Barbosa, D.C.N.; Santos, J.M.; Lemes, L.R.S.; Melo, L.C.S.; Ferreira, R.W.R.; Brandão, R.G.C. (2013). Relatório de estágio supervisionado em formação de professor de psicologia (Relatório de Estágio não 
publicado). Goiânia, Go: Universidade Federal de Goiás,

Berliner, A. (Diretor) (1997). Ma vie en rose [Filme]. France, Belgium, United Kingdom: Haut et Court (France), Sony Pictures Classics (US).

Coelho, I.M. (2003). Repensando a formação de professores. Nuances: Estudos sobre Educação, 9 (9/10), 47-63.

Conselho Regional de Psicologia de São Paulo (2008). Oito Razões para aprender Psicologia no Ensino Médio. Recuperado: 13 set. 2014. Disponível: http://www.pol.org.br/main/oito_motivos.cfm.

Cruz, E.F. (2011). Banheiros, travestis, relações de gênero e diferenças no cotidiano da escolar. Revista Psicologia Política, 11(21), 73-90.

Dadico, L. (2009). Práticas educacionais distintas: a psicologia no ensino médio paulista. Cadernos de Pesquisa, 39(137), 420-440.

Faria, A.L.G. (2006). Pequena infância, educação e gênero: subsídios para um estado da arte. Cadernos Pagu, 26, 279-287.

Foucault, M. (1997). História da sexualidade. Rio de Janeiro: Paz e Terra.

Lei n. 13.415, de 16 de fevereiro de 2017 (2017, 16 de fevereiro). Conversão da Medida Provisória $\mathrm{n}^{\circ} 746$, de 22 de setembro de 2016. Brasília, DF: Presidência da República. Recuperado: 14 de ago. 2017. Disponível: http://www.planalto.gov.br/ccivil_03/_ ato2015-2018/2017/lei/L13415.htm.

Louro, G.L. (2004). Um corpo estranho: ensaios sobre sexualidade e teoria queer. Belo Horizonte: Autêntica.

Louro, G. (2011). Gênero, sexualidade e educação: uma perspectiva pós-estruturalista. Rio de Janeiro: Vozes.

Lüdke, M.; André, M. (1986). Pesquisa em Educação: abordagens qualitativas. São Paulo: EPU.

Nardi, H.C.; Machado, P.S.; Silveira, R.S. (Orgs) (2015). Diversidade sexual e relações de gênero nas políticas públicas: o que a laicidade tem a ver com isso? Porto Alegre: Deriva/ABRAPSO.

Nicholson, L. (2000). Interpretando o gênero. Estudos Feministas, 8(2), 9-41.

Pandita-Pereira, A. (2013). Ensino de Psicologia em Escolas Técnicas de Nível Médio: Por quê? Para quê? Para quem? IN: Sekkel, M.C.; C.C. Barros (Orgs), Licenciatura em Psicologia: temas atuais (pp. 95-113). São Paulo: Zagodoni Editora.

Pandita-Pereira, A.; Sekkel, M.C. (2012). Possibilidades de atuação para o licenciado em Psicologia nas Etecs. Psicologia: Ciência e Profissão, 32(4), 972-985.
Parecern. 403 (1962, 19 de dezembro). Parecer do Conselho Federal de Educação sobre currículo mínimo dos cursos de Psicologia. Brasília, DF: Ministério da Educação e Cultura. Recuperado: 13 de set. 2014. Disponível: www.abepsi.org.br/portal/wpcontent/ uploads/2011/07/1962-parecern403de19621.pdf

Pimenta, S.G.; Lima, M.S.L. (2006). Estágio e docência: diferentes concepções. Revista Poiésis, 3(3/4), 5-24.

Projeto de Lei 105/2007 (2007). Altera dispositivos do art. 36 da Lei n. 9.394, de 20 de dezembro de 1996. Brasília, DF: Câmara dos deputados. Recuperado: 12 set. de 2014.Disponível:http://www. camara.gov.br/proposicoesWeb/fichadetramitacao?idProposic $\mathrm{ao}=340480$.

Resolução n. 8, de 7 de maio de 2004 (2004, 7 de maio). Institui as Diretrizes Curriculares Nacionais para os cursos de graduação em Psicologia. Brasília: Conselho Nacional de Educação.

Resolução n. 5, de 15 de março de 2011 (2011, 15 de março). Institui as Diretrizes Curriculares Nacionais para os cursos de graduação em Psicologia, estabelecendo normas para o projeto pedagógico complementar para a Formação de Professores de Psicologia. Brasília: Conselho Nacional de Educação

Resolução n. 2 de 30 de janeiro de 2012 (2012, 30 de janeiro). Define Diretrizes Curriculares Nacionais para o Ensino Médio. Brasília, DF: Conselho Nacional de Educação. Recuperado: 12 de set. 2014. Disponível: http://portal.mec.gov.br/index.php?option=com content\&view=article\&id=17417\&ltemid=866.

Resolução n. 6 de 20 de setembro de 2012 (2012, 20 de setembro). Define Diretrizes Curriculares Nacionais para a Educação Profissional Técnica de Nível Médio. Brasília, DF: Conselho Nacional de Educação. Recuperado: 12 set. 2014. Disponível: http://portal.mec.gov.br/index.php?option=com_content\&view=arti cle\&id=17417\&ltemid=866.

Scott, J. (1995). Gênero: uma categoria útil de análise histórica. Educação \& Realidade, 20(2), 71-99.

Sekkel, M.C. (2010). Psicologia no Ensino Médio, os desafios de ser professor? Psicologia Ensino \& Formação, 1(2), 73-83.

Shetty, A. (Diretor). (2013). It's Your Fault [Vídeo]. Índia: All India Bakchod.

Soligo, A.; Azzi, R.G. (2009). Psicologia no Ensino Médio. IN: Conselho Federal de Psicologia (Org.), Seminário nacional do ano da educação psicologia: profissão na construção da educação para todos (pp. 55-64). Brasília: CFP. 


\section{Sobre as autoras}

Sheila Daniela Medeiros dos Santos (sheiladaniela@yahoo.com.br)

Graduada em Pedagogia (UNICAMP), Mestre e Doutora em Educação (FE-UNICAMP), Docente da Faculdade de Educação - Curso de Psicologia e Licenciaturas. Universidade Federal de Goiás. Goiás-GO. https://orcid.org/0000-0002-0565-7330

Jordana de Castro Balduino Paranahyba (jordanabalduino@gmail.com)

Graduada em Psicologia (PUC-GO), Mestre e Doutora em Educação (Universidade de Barcelona), Docente da Faculdade de Educação - Curso de Psicologia e Licenciaturas. Universidade Federal de Goiás. Goiás-GO. https://orcid.org/0000-0002-8718-8944

License information: This is an open-access article distributed under the terms of the License (type CC-BY), which permits unrestricted use, distribution and reproduction in any medium, provided the original article is properly cited. 
